\title{
Recent advances in management of cryptococcal meningitis: commentary
}

\author{
Tania C Sorrell* and Sharon C-A Chen
}

\author{
Address: Centre for Infectious Diseases and Microbiology and the University of Sydney at Westmead Hospital, Darcy Road, Westmead, NSW 2145, \\ Australia \\ * Corresponding author: Tania C Sorrell (tania.sorrell@sydney.edu.au) \\ Fl000 Medicine Reports 2010, 2:82 (doi:10.3410/M2-82) \\ This is an open-access article distributed under the terms of the Creative Commons Attribution-Non Commercial License \\ (http://creativecommons.org/licenses/by-nc/3.0/legalcode), which permits unrestricted use, distribution, and reproduction in any medium, \\ provided the original work is properly cited. You may not use this work for commercial purposes. \\ The electronic version of this article is the complete one and can be found at: http://fl000.com/reports/m/2/82
}

\begin{abstract}
Cryptococcal meningitis remains a substantial health burden with high morbidity, particularly in developing countries. Antifungal treatment regimens are guided by host factors, severity of illness (including presence of complications), and causative cryptococcal species. Recent clinical studies indicate the need for rapidly fungicidal induction therapy regimens using amphotericin $B$ in combination with flucytosine for optimal outcomes. Maintenance therapy with fluconazole is necessary until recovery of immune function. Cryptococcus gattii meningitis requires prolonged induction/eradication therapy. Prompt control of raised intracranial pressure or hydrocephalus is essential. Clinicians should be vigilant for immune restoration-like features. Adjuvant surgery, corticosteroids, and/or recombinant interferon-gamma may be required for large cryptococcomas, cerebral edema, or refractory infection.
\end{abstract}

\section{Introduction and context}

Human cryptococcosis is most commonly caused by Cryptococcus neoformans and Cryptococcus gattii, with C. neoformans var. grubii in patients with AIDS accounting for the majority of infections worldwide. Clinical features and complications of infection caused by the two species are influenced by differences in epidemiology and host association (reviewed in $[1,2]$ ). For example, there is a greater propensity for C. gattii than for C. neoformans to cause disease in immunocompetent hosts and to be associated with large mass lesions or cryptococcomas [3]. These differences may influence intervention strategies.

Cryptococcal meningoencephalitis (CM), the most severe form of cryptococcosis, typically affects the highrisk population groups of HIV/AIDS and organ transplantation patients but also affects individuals without apparent immunocompromise [3-5]. Key management issues include the employment of rapidly fungicidal regimens in the induction phase of antifungal treatment followed by adequate suppressive therapy, as well as early recognition and treatment of complications of CM such as raised intracranial pressure (ICP) and the immune response inflammatory syndrome (IRIS) $[1,6,7]$, optimal management of large cerebral cryptococcomas, and treatment strategies in resource-limited settings $[8,9]$.

\section{Recent advances}

Recent advances in clinical research include those directed at better defining prognostic determinants of outcome, especially in HIV-infected individuals, and the application of these findings to treatment algorithms $[10,11]$. The overall management of cryptococcosis is detailed in the new clinical practice guidelines of the Infectious Diseases Society of America [1]. These include specific recommendations for unique risk populations such as children, pregnant women, those with C. gattii infection, and those in in resource-limited environments.

\section{Meningoencephalitis in HIVIAIDS}

Randomized controlled trials (RCTs) of drug therapy of CM due to C. neoformans in HIV/AIDS formalized the concept of induction, consolidation (eradication), and 
Table I. Antifungal treatment for cryptococcal meningoencephalitis and disseminated disease

\begin{tabular}{|c|c|c|c|c|}
\hline Clinical setting & Induction therapy & Duration & Consolidation/maintenance therapy & Duration \\
\hline \multirow[t]{3}{*}{$\begin{array}{l}\text { HIV-infected } \\
\text { individuals }\end{array}$} & $\begin{array}{l}\text { c-AMB }(0.7-1 \mathrm{mg} / \mathrm{kg} \text { daily) plus flucytosine } \\
(100 \mathrm{mg} / \mathrm{kg} \text { daily }) \\
\text { or }\end{array}$ & 2 weeks & $\begin{array}{l}\text { Consolidation: fluconazole ( } 400 \mathrm{mg} \text { daily) } \\
\text { Maintenance: fluconazole ( } 200 \mathrm{mg} \text { daily) }\end{array}$ & 8 weeks \\
\hline & $\begin{array}{l}\text { L-AMB }(3-4 \mathrm{mg} / \mathrm{kg} \text { daily) or ABLC }(5 \mathrm{mg} / \mathrm{kg} \text { daily) } \\
\text { (if there are renal function concerns) plus } \\
\text { flucytosine }(100 \mathrm{mg} / \mathrm{kg} \text { daily) } \\
\text { or }\end{array}$ & 2 weeks & $\begin{array}{l}\text { Itraconazole }(400 \mathrm{mg} \text { daily })^{\mathrm{a}} \\
\text { c-AMB (I mg/kg per week })^{\mathrm{a}}\end{array}$ & $\geq 1$ year $^{b}$ \\
\hline & $\begin{array}{l}\text { c-AMB or L-AMB or ABLC (doses as above) for } \\
\text { flucytosine-intolerant patients }\end{array}$ & 4-6 weeks & & $\geq$ I year ${ }^{b}$ \\
\hline \multirow[t]{2}{*}{$\begin{array}{l}\text { Organ transplant } \\
\text { recipients }\end{array}$} & $\begin{array}{l}\text { L-AMB }(3-4 \mathrm{mg} / \mathrm{kg} \text { daily) or ABLC ( } 5 \mathrm{mg} / \mathrm{kg} \text { daily }) \\
\text { plus flucytosine }(100 \mathrm{mg} / \mathrm{kg} \text { daily }) \\
\text { or }\end{array}$ & 2 weeks & $\begin{array}{l}\text { Consolidation: fluconazole (400-800 mg daily) } \\
\text { Maintenance: fluconazole ( } 200-400 \mathrm{mg} \text { daily) }\end{array}$ & 8 weeks \\
\hline & $\begin{array}{l}\text { L-AMB }(6 \mathrm{mg} / \mathrm{kg} \text { daily }) \text { or } \mathrm{ABLC}(5 \mathrm{mg} / \mathrm{kg} \text { daily }) \text { or } \\
\text { c-AMB }(0.7 \mathrm{mg} / \mathrm{kg} \text { daily })\end{array}$ & 4-6 weeks & & $6-12$ months \\
\hline \multirow[t]{2}{*}{$\begin{array}{l}\text { Non-HIV, non- } \\
\text { transplant patients }\end{array}$} & $\begin{array}{l}\text { c-AMB }(0.7-1 \mathrm{mg} / \mathrm{kg} \text { daily }) \text { plus flucytosine } \\
(100 \mathrm{mg} / \mathrm{kg} \text { daily }) \\
\text { or }\end{array}$ & $\geq 4$ weeks & $\begin{array}{l}\text { Consolidation: fluconazole ( } 400-800 \mathrm{mg} \text { daily) } \\
\text { Maintenance: fluconazole ( } 200 \mathrm{mg} \text { daily) }\end{array}$ & 8 weeks \\
\hline & $\begin{array}{l}\text { L-AMB ( } 3-4 \mathrm{mg} / \mathrm{kg} \text { daily) or ABLC ( } 5 \mathrm{mg} / \mathrm{kg} \text { daily) } \\
\text { plus flucytosine } \\
\text { c-AMB or L-AMB or ABLC (in above doses) } \\
\text { without flucytosine }\end{array}$ & $\geq 6$ weeks & & $6-12$ months \\
\hline
\end{tabular}

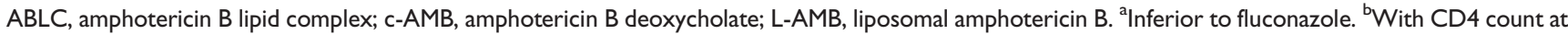
least 100 cells per microliter and undetectable viral load for at least 3 months with a minimum of I year of antifungal therapy.

maintenance (suppression) antifungal therapy in the severely immunosuppressed (Table 1) [1]. Rapidly fungicidal induction therapy regimens are essential for favorable outcomes [12]. In particular, combined amphotericin $\mathrm{B}(\mathrm{AMB})$-flucytosine regimens result in faster sterilization of cerebrospinal fluid (CSF) and superior clinical or mycological outcomes at 2 weeks and at 3 months in comparison with $\mathrm{AMB}$ alone, $\mathrm{AMB}$ plus fluconazole, or fluconazole alone $[10,11,13]$. This difference has been most evident in patients with high initial CSF fungal burdens or abnormal neurological features (or both) at presentation. Conversely, receipt of initial flucytosine for fewer than 14 days has been independently linked with treatment failure at 3 months of therapy [11]. Nonetheless, the only large randomized phase III study of AMB with and without flucytosine (in patients with AIDS) failed to demonstrate a clinical benefit of combination therapy [14]. Conventional AMB (c-AMB) at a daily dose of $1 \mathrm{mg} / \mathrm{kg}$ (in combination with flucytosine) is more rapidly fungicidal than a dose of $0.7 \mathrm{mg} / \mathrm{kg}$ [10]; duration of therapy depends on clinical response and treatment regimen (Table 1). Although there are fewer reports of lipid $\mathrm{AMB}$ formulations in combination with flucytosine for treating $\mathrm{CM}$, clinical experience strongly suggests that such combination therapy is effective (reviewed in [1]) and there is consensus that either liposomal AMB (3-4 mg/kg daily) or AMB lipid complex ( $5 \mathrm{mg} / \mathrm{kg}$ daily) could be substituted for C-AMB in patients with or predisposed to renal dysfunction [1].

Induction regimens with fluconazole plus flucytosine or with fluconazole monotherapy have been used, especially in resource-limited areas (see below), but are less effective and are indicated only when first-line drugs cannot be used [1]. If fluconazole is to be used as a single agent, a daily dose of $1200-2000 \mathrm{mg}$ is recommended $[15,16]$. Following induction/consolidation therapy, fluconazole should be continued until immune reconstitution with HAART (highly active antiretroviral therapy) [1]. Voriconazole and posaconazole can be used as salvage therapy for all patient groups (see below) [1].

When C. gattii affects patients with AIDS, clinical features appear to be similar to those of $C$. neoformans var. grubii [17], suggesting that management should also be similar. There are retrospective data showing that the course and outcomes of CM (without cerebral mass lesions or hydrocephalus) are independent of causative cryptococcal species [1].

\section{Meningoencephalitis in organ transplantation}

Given the likelihood of nephrotoxicity with concurrent use of c-AMB and calcineurin inhibitors and given that approximately $25 \%$ of all organ recipients with cryptococcosis have renal dysfunction, lipid AMB formulations are often employed as induction therapy in combination with flucytosine (Table 1). The median time to CSF sterilization is approximately 10 days, and 2-6 weeks of induction therapy (depending on whether flucytosine is given) are recommended [1]. Recently, it was documented for the first time in solid-organ transplant recipients that the use of lipid AMB formulations to treat CM independently predicted better outcomes (compared with c-AMB) [5]. However, clinical outcomes were measured at 90 days, 
did not include late complications, and did not specifically evaluate efficacy of different antifungal therapies. There are data to suggest that calcineurin inhibitors demonstrate synergistic effects in vitro with antifungal agents and may be associated with better outcomes in solid-organ transplant patients with cryptococcosis [18].

Since most relapses in patients not prescribed maintenance therapy occur within 6 months $[1,19]$, consolidation/maintenance fluconazole therapy for 6-12 months (relapse rate of $1.3 \%$ ) is recommended. Azole-drug interactions may be problematic. Reduction of immunosuppressive therapy should be gradual to minimize the risk of allograft loss and development of IRIS [6,19].

\section{Neurocryptococcosis in non-immunocompromized hosts} In uncomplicated $C$. neoformans meningitis, opinion (there are no RCT data) favors induction with c-AMB or a lipid formulation and flucytosine for 2 weeks (in the absence of adverse prognostic factors such as abnormal neurological findings or altered mental status) or 4-6 weeks provided that 2-week CSF cultures are negative [1] (Table 1). One recent retrospective study of 154 patients without HIV/ AIDS, of whom 103 had no immune compromise, reported that initial therapy with non-AMB-containing regimens was independently associated with increased mortality [20]. Experts treating C. gattii meningitis also favor 4-6 weeks of therapy on the basis of clinical experience [1]. Although fluconazole (with or without flucytosine) is not recommended for induction therapy, it is the drug of choice ( $400 \mathrm{mg} /$ day) for eradication (8 weeks) and maintenance (6-12 months) therapy to prevent relapse. Compared with C. neoformans, intracranial C. gattii infection is associated with a greater number of neurological sequelae and delayed responses to therapy, primarily because of a higher proportion of cerebral mass lesions (cryptococcomas) and late presentations $[1,3]$.

\section{Other management}

Another important determinant of outcome is control of raised ICP by repeated lumbar puncture and/or by early shunting; symptomatic hydrocephalus requires antifungal therapy plus early shunting $[1,2]$. In the absence of cryptococcomas, the antifungal regimen should be the same as for meningitis. Large cryptococcomas should be treated with combination antifungal therapy and early surgical removal as response to antifungal drugs is poor. Multiple lesions require prolonged induction/eradication therapy [3]. Corticosteroids may be required if there is substantial surrounding edema, especially in the presence of neurological deficits [1].

The duration of induction/eradication antifungal therapy depends on clinical and mycological responses.
Re-imaging in cases of apparent relapse may reveal new/ enlarging lesions, with increased perilesional edema despite antifungal therapy. This appears to result from IRIS, as has been reported for C. gattii infection and organ transplant/HIV-positive patients following recovery of immune function. Apart from enhancing central nervous system (CNS) lesions, C. neoformans-associated IRIS may manifest in the CNS as increased ICP and inflammatory lesions within the spinal cord and typically also presents as lymphadenitis, skin, or soft tissue lesions [6,7]. Short-course corticosteroids have been used successfully alongside antifungal therapy $[6,21,22]$. Adjunctive recombinant interferon-gamma therapy has been tried in C. gattii infection unresponsive to repeated/prolonged courses of antifungal drugs $[1,2]$. Its contribution to outcomes is uncertain.

\section{Resource-limited settings}

Treatment of $\mathrm{CM}$ in areas where only $\mathrm{C}-\mathrm{AMB}$ and fluconazole are widely available has been recently assessed. Donated fluconazole (200-400 mg daily) for 8-10 weeks is often the only treatment option, especially in Africa [23], but there are no data to recommend fluconazole as first-line therapy [9]. The only study comparing the efficacy of fluconazole and c-AMB is an older American study that showed non-inferiority between the two agents. This study, however, had excluded severely ill patients, included patients who were undergoing re-treatment of their infection, and had employed a low dose of c-AMB (0.3 mg/kg daily) [24].

In developed countries, flucytosine-AMB combinations are the preferred induction treatment regimens in HIV/ AIDS. Where flucytosine-AMB combinations are not available, relevant authorities should consider procuring flucytosine for $\mathrm{CM}$ treatment programs. Antifungal prophylaxis programs have shown mixed results [22].

\section{Implications for clinical practice}

Major determinants of outcome of CM include neurological status, ICP, presence of cerebral mass lesions, and cryptococcal load at presentation. CSF pressure should always be assessed and raised ICP relieved promptly. Rapidly fungicidal induction treatment regimens are the key to optimal outcomes in all patients. Flucytosine, in combination with $\mathrm{AMB}$, remains the induction regimen of choice; the importance of flucytosine has been demonstrated in a number of studies and RCTs. In organ transplant patients, use of lipid AMB, over C-AMB, has been linked with superior outcomes. Longer courses of induction/eradication therapy are required in C. gattii infection. Shunting to relieve symptomatic hydrocephalus, and resection of large cryptococcomas, usually due to C. gattii, may be necessary. In patients with substantial 
cerebral edema and/or IRIS, corticosteroids may be required to control the pathogenic process.

\section{Abbreviations}

$\mathrm{AMB}$, amphotericin $\mathrm{B}$; C-AMB, conventional amphotericin B; CM, cryptococcal meningoencephalitis; CNS, central nervous system; CSF, cerebrospinal fluid; ICP, intracranial pressure; IRIS, immune response inflammatory syndrome; RCT, randomized controlled trial.

\section{Competing interests}

The authors declare that they have no competing interests.

\section{References}

I. Perfect JR, Dismukes WE, Dromer F, Goldman DL, Graybill JR, Hamill RJ, Harrison TS, Larsen RA, Lortholary O, Nguyen MH, Pappas PG, Powderly WG, Singh N, Sobel JD, Sorrell TC: Clinical practice guidelines for the management of cryptococcal disease: 2010 update by the Infectious Diseases Society of America. Clin Infect Dis 2010, 50:291-322.

\section{Changes Clinical Practice}

FI000 Factor 6

Evaluated by Stephane Bretagne 03 Feb 2010

2. Pukkila-Worley R, Mylonakis E: Epidemiology and management of cryptococcal meningitis: developments and challenges. Expert Opin Pharmacother 2008, 9:55I-60.

3. Mitchell DH, Sorrell TC, Allworth AM, Heath $\mathrm{CH}$, McGregor AM, Papanaoum K, Richards MJ, Gottlieb T: Cryptococcal disease of the CNS in immunocompetent hosts: influence of cryptococcal variety on clinical manifestations and outcome. Clin Infect Dis 1995, 20:611-6.

4. Park BJ, Wannemuehler KA, Marston BJ, Govender N, Pappas PG, Chiller TM: Estimation of the current global burden of cryptococcal meningitis among persons living with HIVI AIDS. AIDS 2009, 23:525-30.

FI000 Factor 8

Evaluated by Tania Sorrell 25 Mar 2009

5. Sun HY, Alexander BD, Lortholary O, Dromer F, Forrest GN, Lyon GM, Somani J, Gupta KL, del Busto R, Pruett TL, Sifri CD, Limaye AP, John GT, Klintmalm GB, Pursell K, Stosor V, Morris MI, Dowdy LA, Munoz P, Kalil AC, Garcia-Diaz J, Orloff S, House AA, Houston S, Wray D, Huprikar S, Johnson LB, Humar A, Razonable RR, Husain S, Singh N: Lipid formulations of amphotericin B significantly improve outcome in solid organ transplant recipients with central nervous system cryptococcosis. Clin Infect Dis 2009, 49:1721-8.

FI000 Factor 10

Evaluated by David Goldman 24 Nov 2009, Tania Sorrell 15 Dec 2009

6. Sun HY, Singh $\mathrm{N}$ : Immune reconstitution inflammatory syndrome in non-HIV immunocompromised patients. Curr Opin Infect Dis 2009, 22:394-402.

7. Singh N, Perfect J: Immune reconstitution syndrome associated with opportunistic mycoses. Lancet Infect Dis 2007, 7:395-40I.

8. Sloan DJ, Dedicoat MJ, Lalloo DG: Treatment of cryptococcal meningitis in resource limited settings. Curr Opin Infect Dis 2009, 22:4554-63.

9. Sloan D, Dlamini S, Paul N, Dedicoat M: Treatment of acute cryptococcal meningitis in HIV infected adults, with an emphasis on resource-limited settings. Cochrane Database Syst $\operatorname{Rev} 2008,4: C D 005647$.

FI000 Factor 6

Evaluated by Francoise Dromer 22 Jan 2010

10. Bicanic T, Wood R, Meintjes G, Rebe K, Brouwer A, Loyse A, Bekker L-G, Jaffar S, Harrison T: High-dose amphotericin B with flucytosine for the treatment of cryptococcal meningitis in HIV-infected patients: a randomized trial. Clin Infect Dis 2008, 47:123-30

FI000 Factor 8

Evaluated by Mark Nicol II Jun 2008, Jeremy Day I 8 Jun 2008, Tania Sorrell 30 Jun 2008

II. Dromer F, Bernede-Bauduin C, Guillemot D, Lortholary O; French Cryptococcosis Study Group: Major role for amphotericin B-flucytosine combination in severe cryptococcosis. PLoS One 2008, 3:e2870.

12. Bicanic T, Muzoora C, Brouwer AE, Meintjes G, Longley N, Taseera K, Rebe K, Loyse A, Jarvis J, Bekker LG, Wood R, Limmathurotsakul D, Chierakul W, Stepniewska K, White NJ, Jaffar S, Harrison TS: Independent association between rate of clearance of infection and clinical outcome of HIV-associated cryptococcal meningitis: analysis of a combined cohort of $\mathbf{2 6 2}$ patients. Clin Infect Dis 2009, 49:702-9.

13. Bicanic T, Meintjes G, Wood R, Hayes M, Rebe K, Bekker LG, Harrison T: Fungal burden, early fungicidal activity, and outcome in cryptococcal meningitis in antiretroviral-naive or antiretroviral-experienced patients treated with amphotericin B or fluconazole. Clin Infect Dis 2007, 45:76-80.

14. van der Horst CM, Saag MS, Cloud GA, Hamill RJ, Graybill JR, Sobel JD, Johnson PC, Tuazon CU, Kerkering T, Moskovitz BL, Powderly WG, Dismukes WE: Treatment of cryptococcal meningitis associated with the acquired immunodeficiency syndrome. N Engl J Med 1997, 337:15-2I.

15. Milefchik E, Leal MA, Haubrich R, Bozette SA, Tilles JG, Leedom JM, McCutchan JA, Larsen RA: Fluconazole alone or combined with flucytosine for the treatment of AIDS-associated cryptococcal meningitis. Med Mycol 2008, 46:393-5.

16. Nussbaum JC, Jackson A, Namarika D, Phulusa J, Kenala J, Kanyemba C, Jarvis JN, Jaffar S, Hosseinipour MC, Kamwendo D, van der Horst CM, Harrison TS: Combination flucytosine and high-dose fluconazole compared with fluconazole monotherapy for the treatment of cryptococcal meningitis: a randomized trial in Malawi. Clin Infect Dis 2010, 50:338-44.

17. Morgan J, McCarthy KM, Gould S, Fan K, Athington-Skaggs B, Iqbal N, Stamey, Hajieh RA, Brandt ME; Gauteng Cryptococcal Surveillance Initiative Group: Cryptococcus gattii infection: characteristics and epidemiology in a South African Province with high HIV seroprevalence, 2002-2004. Clin Infect Dis 2006, 43:1077-80.

18. Kontoyiannis DP, Lewis RE, Alexander BD, Lortholary O, Dromer F, Gupta KL, John GT, Del Busto R, Klintmalm GB, Somani J, Lyon GM, Pursell K, Stosor V, Munoz P, Limaye AP, Kalil AC, Pruett TL, GarciaDiaz J, Humar A, Houston S, House AA, Wray D, Orloff $S$, Dowdy LA, Fisher RA, Heitman J, Albert ND, Wagener MM, Singh N: Calcineurin inhibitors agents interact synergistically with antifungal agents in vitro against Cryptococcus neoformans isolates: correlation with outcome in solid organ transplant recipients with cryptococcosis. Antimicrob Agents Chemother 2008, 52:735-8.

19. Singh N, Dromer F, Perfect JR, Lortholary O: Cryptococcosis in solid organ transplant recipients: current state of the science. Clin Infect Dis 2008, 47:1321-7.

20. Zhu L-P, Wu J-Q, Ou X-T, Zhang Q-Q, Weng X-H: Cryptococcal meningitis in non-HIV-infected patients in a Chinese tertiary care hospital. Med Mycol 2010, 48:570-9. 
21. Philips P, Chapman K, Sharp M, Harrison P, Vortel J, Steiner T, Bowie W: Dexamethasone in Cryptococcus gattii central nervous system infection. Clin Infect Dis 2009, 49:591-5.

FI000 Factor 6

Evaluated by Tania Sorrell II Aug 2009

22. Jarvis JN, Dromer F, Harrison TS, Lortholary O: Managing cryptococcosis in the immunocompromised host. Curr Opin Infect Dis 2008, 21:596-603.
23. Makombe SD, Nkhata A, Schouten EJ, Kamoto K, Harries AD: Burden of cryptococcal meningitis in Malawi. Trop Doct 2009, 39:32-4.

24. Saag MS, Powderly WG, Cloud GA, Robinson P, Grieco MH, Sharkey PK, Thompson SE, Sugar AM, Tuazon CU, Fisher JF, Hyslop N, Jacobson JM, Hafner R, Dismukes WE; NIAID Mycoses Study Group; AIDS Clinical Trials Group: Comparison of amphotericin B with fluconazole in the treatment of acute AIDSassociated cryptococcal meningitis. N Engl J Med 1992, 326:83-9. 